ment work, he advocates the formation of a corporation of the type of Research Enterprises Ltd. managed by the National Research Council of Canada. Such a development corporation should be encouraged to take risks by an annual State grant, and introduce into industry and agriculture the inventions and processes worked out under the national research council.

\section{New Light on the Inductive Method}

EvERYONE who is interested in the foundations of scientific method will find it worth while to read the article entitled "Hr. Von Wright on the Logic of Induction" which appears in the issue of Mind of January 1944, from the pen of Prof. C. D. Broad. It is Prof. Broad's account of the attack on the problem of induction which $\mathrm{Hr}$. Von Wright has made in his published works consisting of a thesis (in English) and an article (in Swedish) on logical subjects. Prof. Broad deserves our thanks for bringing the content of these two works to the attention of English logicians. This article not only presents a remarkable original contribution of the Swedish logician but also reveals Dr. Broad's own illuminating comments upon it. It is impossible to summarize the argument adequately in a few sentences. The article begins by pointing out that where an unlimited sequence of instances is concerned, the proposition " $100 \%$ of the $Q$ 's are $R$ 's" does not entail the proposition "All the $Q$ 's are $R$ ' $s$ ". The nucleus of the problem of induction is, "How can we pass from propositions of the former type based on a finite number of $Q$ 's to propositions of the latter type ?" The attempt to justify such a passage by a priori argument is neatly refuted by a proof both ingenious and conclusive. The attempt to justify it by arguments a posteriori leads to a discussion of how in practice the necessary and/or sufficient conditions of a phenomenon are established. The question then arises : "Can we infer with certainty by such means general propositions about the necessary or sufficient conditions of a given characteristic $Q$ ?" The answer, very briefly, is : "Not without the help of postulates". These postulates are either a priori propositions, which is proved impossible, or inductive generalizations, which would lead to a vicious circle. Hence no justification of inductive generalization along these lines is possible.

\section{Radio-Frequency Heating}

At an informal meeting of the Institution of Electrical Engineers held in London on January 24, the industrial applications of radio-frequency methods of heating were discussed, and the opening speaker was Mr. N. R. Bligh. The two main fields of application were eddy current heating and capacitance current heating. A third heating field was where the use of radio-frequency currents was only involved because such currents could be led into the charge through small capacitances; the actual heating process, however, was of the resistance heating class. The valve generator appears to be capable of generating all the power yet required for any application, even up to the highest frequencies of some hundreds of megacycles, and $\mathrm{Mr}$. Bligh suggested that the only power rating which should be stated for a radiofrequency generator is its power output into its optimum resistance load, though for convenience the volt-ampere rating might also be given. The selfoscillator was regarded as the simplest form of generator, and up to a few hundred watts, glass envelope valves could be used, but beyond this, external anode valves were preferable.

Regarding the load circuits proper, the charge is placed between condenser plates for capacitance current heating with one side of the load preferably at earth potential. In the case of eddy current heating the heating coil should be as tightly coupled to the charge as mechanical and electrical conditions allow. Applications of capacitance current heating are the completion of the dehydration of food, and the bonding of thin layers of thermoplastic materials such as vinyl resins and the cellulose esters. Eddy current heating has been used for some time in the production of thermionic valves, while the heat treating of surfaces and heating of very small items are becoming increasingly common.

\section{Electricity Supply System Load Analysis}

IN a paper read in London on March 16 before the Institution of Electrical Engineers by Mr. P. Schiller, an analysis is presented of the load on the system of the Northmet Power Co. during the year ended June 30,1939 . The block of annual load is split up into a basic or all-the-year-round portion, and a seasonal portion, the latter representing all the consumption due to space heating and about half that due to lighting. The basic portion is sub-divided into its principal components, and for the seasonal portion, an attempt is made to separate lighting load and space-heating load, in respect of both demand and annual consumption. Seasonal demand curves are developed, in which the load at a certain time of day is plotted for a series of days, and compared with the simultaneous conditions of outdoor temperature and illumination. The annual load factors of modern lighting and space-heating loads are found to be normally of equal order of magnitude ; in a year with a cold snap the load factor of the latter may even be considerably lower than that of the former. Characteristic collective and component load curves are given, and graphs are presented dealing particularly with the space-heating load. The paper concludes with recommendations for further research.

\section{Electrical Installation Equipment}

A PAPER entitled "The Influence of Maintenance Requirements on the Design of Electrical Installation Equipment", read in London on March 9 by Mr. $H$. Drake before the Institution of Electrical Engineers, points out the weaknesses of electrical installation equipment from the maintenance point of view with particular reference to domestic and commercial installations ; in addition, a fow comments are given on industrial equipment, the design of which seems far more satisfactory. Wherever possible, improvements and remedies which are commercially practicable are suggested. The equipment has been considered under the headings of switch and control gear, cables and cable accessories, wiring systems and accessories, utilization, including domestic, commercial and agricultural applications, and industrial plant. In general, complaints fall into the four main categories of insufficient space for wiring, inadequate terminal arrangements, lack of standardization and lack of appreciation of the innate clumsiness of the general public. If manufacturers' future designs overcome these four fundamental difficulties, much perplexity will be saved in the maintenance and installation industry. 